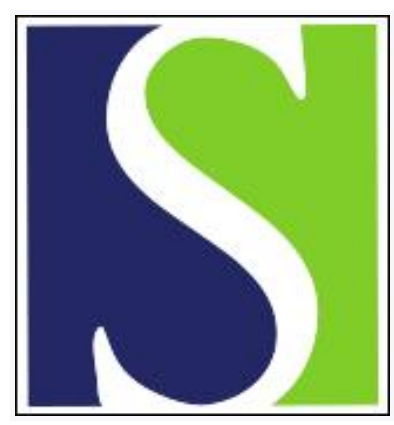

Scand J Work Environ Health 1977;3(1):28-31

https://doi.org/10.5271/sjweh.2794

Issue date: Mar 1977

Evaluation of chromium exposure based on a simplified method for urinary chromium determination.

by Gylseth B, Gundersen N, Langård S

Key terms: chromium excretion; chromium exposure; urinary chromium; urinary chromium determination; welder

This article in PubMed: www.ncbi.nlm.nih.gov/pubmed/847428

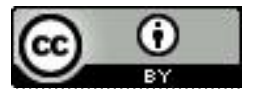




\title{
Evaluation of chromium exposure based on a simplified method for urinary chromium determination
}

\author{
by BJØRN, GYLSETH, M.Sc., NILS GUNDERSEN, M.Sc., and SVERRE \\ LANGÅR, M.D. ${ }^{1}$
}

\begin{abstract}
GYLSETH, B., GUNDERSEN, N. and LANGARD, S. Evaluation of chromium exposure based on a simplified method for urinary chromium determination. Scand. $j$. work environ. \& health 3 (1977) 28-31. The urine chromium levels for unexposed and chromium exposed persons were determined by a simplified method which is well suited for routine, large-scale use. A group of weldens working on chromium alloyed steel were investigated. For these welders a high degree of correlation was found between the concentration of inhaled chromium and the chromium concentration in the urine immediately after work. At an exposure level of $0.05 \mathrm{mg} / \mathrm{m}^{3}$, measured as chromium, a urinary chromium concentration of approximately $40 \mu \mathrm{g} / 1$ was measured after work. This urinary chromium level is suggested as a guideline indicating the need for a thorough investigation of chromium exposure.
\end{abstract}

Key words: chromium excretion, chromium exposure, welders.

The health hazards of human exposure to chromium include corrosive damage to mucous membranes and the skin, hypersensitivity, and an increased risk for lung cancer. Most of these health hazards have been described after exposure to hexavalent chromium compounds, but trivalent chromium compounds may be important in the induction of allergic reactions, and they are also mentioned as having a carcinogenic effect $(4,7,10,11,17)$. As far as the carcinogenic effect of hexavalent chromium is concerned, no conclusions on the dose-response relationship can be drawn from the information presented in existing literature. Therefore, it would be of value to establish dose indicators for use in epidemiologic work and to be able to judge the degree of health hazard

\footnotetext{
1 Institute of Occupational Health, Oslo, Norway.
}

Reprint requests to: Mr. B. Gylseth, Institute of Occupational Health, P.O.B. 8149, DEP Oslo 1, Norway. related to various work operations. Biological sampling is a valuable tool for establishing such dose criteria.

Different analytical methods for the determination of trace amounts of chromium in human urine have previously been reported in the literature $(2,3,5,6$, $12,13,14,15,16,18,19)$. The wide range of normal values reported, $0-50 \mu \mathrm{g} / 1$ of urine, definitely depend on geographical variations, differences in nutritional and drinking habits, and differences in methodology as well. The urinary chromium level of workers exposed to hexavalent chromium has been reported to be as high as $140 \mu \mathrm{g} / 1$ of urine $(12,14,18)$.

When dose indicators for use in epidemiologic studies and for routine tests in the evaluation of workplaces are established, it is important that the sampling methods be suitable for use on a large scale and that the analyses be easily performed in an ordinary laboratory. Urine samples are quite easy to collect from workers; therefore this sampling method 
is very suitable for large-scale screening purposes. In this paper we report a simplified method for the analytical determination of chromium in urine. The urinary chromium content used for chromium exposure evaluations of workers who weld alloyed steel is reported as an example.

\section{SAMPLING AND ANALYTICAL METHODS}

The urine samples were collected in $250-\mathrm{ml}$ polyethylene bottles which were thoroughly washed and cleaned at the laboratory and to which $0.1 \mathrm{~g}$ of $\mathrm{Na}_{4}$ EDTA was added before use. New pyrex glass equipment and reagent-grade chemicals contained unacceptable amounts of chromium when we operated at the parts-per-billion level.

The glass equipment was boiled twice in $1: 1$ aqua regia and kept overnight in double-distilled reagent-grade nitric acid $(1: 1)$. Before use the glass equipment was thoroughly washed with distilled water. All other chemicals used were p.a. quality from Merck.

Fifty-milliliter urine samples were added to $5 \mathrm{ml}$ of double-distilled nitric acid and evaporated in $100-\mathrm{ml}$ glass beakers to an approximate volume of $7 \mathrm{ml}$, when nitrous gases appear. The beaker was then covered with a watch glass and the solution was evaporated to dryness. When the color of the residue became yellowish white, the residue was dissolved in $2 \mathrm{ml}$ of nitric acid and the glass equipment was rinsed with distilled water to a total volume of $10 \mathrm{ml}$.

When the color became brownish, $2 \mathrm{mI}$ of acid was added, and the solution was evaporated a second time and then dissolved as described previously.

Since dry-ashing yields an ash with a low solubility and contamination from the muffle-oven can occur, a low-temperature wet-ashing method was preferred for the urine and the formation of insoluble oxides and phosphates was therefore prevented. The method also provides a fivefold increase in concentration.

A Perkin-Elmer model 300 atomic absorption spectrophatometer connected to a Perkin-Elmer model 56 recorder was employed in this investigation, along with the maximum sensitivity of the chromium 3579 A line. A reducing air/acetylene flame was used for the atomization. The apparatus was optimalized with test solution standards of $10-200 \mu \mathrm{g} / \mathrm{l}$, prepared from potassium chromate. Based on the signal to noise ratio, the practical detection limit of chromium in urine for this system is approximately $2 \mu \mathrm{g} / \mathrm{l}$. Approximately $2 \mu \mathrm{g} / \mathrm{l}$ of chromium was obtained for the acid-blind analysis.

Spectral interferences may arise from absorption because of the light scattering and molecular absorption. The analysis of water standards containing salts that correspond to those found in urine showed minor interferences.

A series of urine specimens was analyzed with the standard addition method. From one sample to another the interferences seemed to be approximately constant, and a constant calibration factor could well be used. Known amounts of chromium were added to some specimens, and a recovery of $80-100 \%$ was achieved. However, a more detailed discussion of interference problems concerning the determination of chromium in urine will be published elsewhere.

The dust samples were collected on $37 \mu \mathrm{mm}, \quad 0.8 \mu \mathrm{m}$ Millipore membrane filters with Casella personal air samplers. The filter monitors were mounted in the breathing zone of the welders.

The dust samples were collected at a rate of $2 \mathrm{l} / \mathrm{min}$ for $7-8 \mathrm{~h}$ of the shift. Before use, the filters were desiccated for $24 \mathrm{~h}$ in a desiccator and weighed with an accuracy of $\pm 0.1 \mathrm{mg}$. After the samples were collected, the filters were desiccated in the same manner and wet-digested according to the method of Langmyhr and Paus (8). The samples were analyzed with the same instrument parameter settings as mentioned earlier.

A series of urine specimens was collected from five welders before and after work on five subsequent days. One welder (group 1) was working on a steel tank of $26 \%$ chromium and $20 \%$ nickel alloyed steel, two (group 2) were welding on $18 \%$ chromium and $8 \%$ nickel alloyed steel, and two (group 3) were working on cylindric milk tanks consisting of $18 \%$ chromium and $9 \%$ nickel alloyed steel. 


\section{RESULTS}

To test the reproducibility of the method, we analyzed randomized urine samples from unexposed persons twice, with a four-day interval inbetween. For a total of 14 samples the first analysis showed a mean value of $8.8 \mu \mathrm{g} / 1$ of urine with $95 \%$ confidence limits of $4.8-12.8 \mu \mathrm{g} / 1$ that suggested a normal distribution. The second analysis showed a mean value of $11.3 \mu \mathrm{g} / 1$ with $95 \%$ confidence limits of $7.2-15.4 \mu \mathrm{g} / \mathrm{l}$. There was a statistically significant difference between the mean values of the two analyses. This difference should be expected because the concentration levels were so low. A normal level below $15 \mu \mathrm{g} / \mathrm{l}$ of urine for this group could be estimated at this probability level.

The relation between urinary chromium excretion and chromium concentrations in the air is presented in fig 1 . The statistical calculations show a statistically significant correlation, $r=0.95$, between the total chromium exposure and the chromium concentration in the urine after work, for 22 degrees of freedom, $t=14.9, \mathrm{p}<0.001$.

Fig. 2 presents the results of the urine chromium concentration of the first welder before and after the work shift, respectively. These results indicate that the absorption and excretion of chromium occur fast. The results are too few however for an estimation of the exact half-time of chromium excretion.

\section{DISCUSSION}

This investigation shows a statistically significant correlation between the chromium exposure of welders working on chromium alloyed steel and their urinary chromium concentration after work.

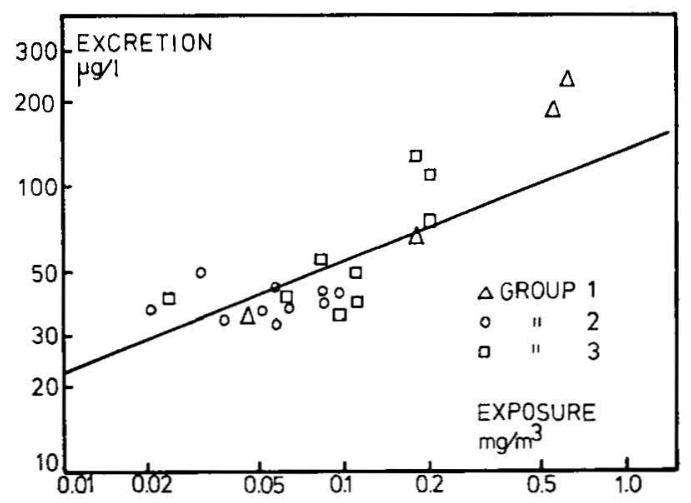

Fig. 1. Relation between the urinary chromium excretion of three groups of wielders and the concentration of chromium in the air during a work shift.

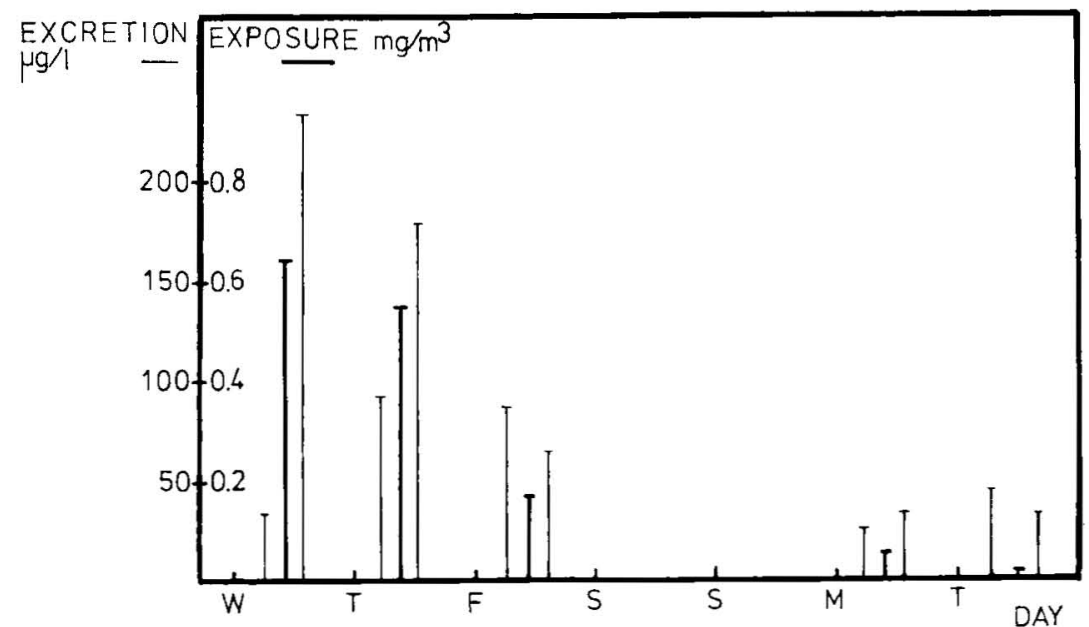

Fig. 2. The urinary chromium concentrations of the welder in group 1 before and after the work shift, respectively. 
The rapid absorption and excretion of the chromium indicates that the absorbed portion consists mainly of hexavalent chromium (9).

When it is assumed that most of the chromium compounds in welding fumes consist of soluble hexavalent chromium, a urinary chromium concentration of $40-$ $50 \mu \mathrm{g}$ of chromium per liter of urine immediately after work would correspond to the threshold limit value of 0.05 of chromium per cubic meter of air recommended by the American Conference of Governmental Industrial Hygienists (1).

Nevertheless the differences due to nutritional and drinking habits, as well as individual variation in urine excretion and density, will make it difficult to state an exact biological threshold limit value. However, for the group of workers in our study this method could be used as an indicator of the need for atmospheric hygienic evaluations. Values of approximately $40-50 \mu \mathrm{g}$ of chromium/liter of urine and higher should initiate a thorough investigation of chromium exposure.

Because of the lack of documentation on the carcinogenic risk at different levels of hexavalent chromium in the work atmosphere, this screening method cannot be adopted for the evaluation of potential carcinogenic risks.

\section{REFERENCES}

1. AMERICAN CONFERENCE OF GOVERNMENTAL INDUSTRIAL HYGIENISTS. Threshold limit values for chemical substances and physical agents in the workroom environment with intended changes for 1975. Cincinnati, Ohio 1975.

2. BEYERMANN, $K$. The determination of nanogram amounts of chromium in urine by X-ray fluorescence spectroscopy. Anal. chim. acta 45 (1969) 51-55.

3. DAVIDSON, I. W. F. and SECREST, W. L. Determination of chromium in biological materials by atomic absorpition spectrometry using a graphite furnace atomizer. Anal. chem. 44 (1972) 1808-1813.

4. FREGERT, S. and RORSMAN, H. Allergy to trivalent chromium. Arch. dermatol. 90 (1964) 4-6.

5. HAMBIDGE, K. IM. Use of static argon atmosphere in emission spectrochemical determination of chromium in biological materials. Anal. chem. 43 (1973) 103-107.

6. IMBUS, H. R., CHOLAK, J., MILLER, L. H. and STERLING, T. Boron, cadmium, chromium and nickel in blood and urine. Arch. environ. health 6 (1963) 286-295.

7. LANGARD, S. and NORSETH, T. A cohort study of bronchial carcinomas in workers producing chromate pigments. $B r . j$. ind. med. 32 (1975) 62-65.

8. LANGMYHR, F. J. and PAUS, P. E. The analysis of inorganic siliceous materials by atomic absorption spectrophotometry and the hydrofluoric acid decomposition technique: Part I. Anal. chim. acta 43 (1968) $397-408$.

9. LASKIN, S, and ISLOA, D. Clearence and distribution of chromium following inhalation exposures. In: Abstracts of technical papers. American industrial hygiene conference, San Francisco May 14-19, 1972, p. 66.

10. LUMIO, J. S. Om skador i de övre andningsvägarna hos förkromare. Nord. hyg. tidskr. 34 (1953) 86-91.

11. MANCUSO, T. F. Consideration of chromium as an industrial carcinogen. Presented at the International Conference of Heavy Metals in the Environment, Toronto, Ontario, Canada Oct. 27-31, 1975.

12. MATSUOKA, C. A. A method determining chromium in human urine by atomic absorption spectroscopy and the application of this method. Jpn. j. ind. health 13 (1971) $27-39$.

13. PERKIN-ELMER APPLICATION NOTE. Trace elements in urine-determination of chromium in urine. Bodenseewerk PerkinElmer \& Co GMBH, Überlingen, Bodensee.

14. PATTY, F. A. (ed.). Industrial hygiene and toxicology (second revised edition). Interscience Publishers, New York, N.Y. 1958, vol. I-II.

15. ROSS, R. T. and GONZALES, J. G. The direct determination of chromium in urine by selective volatilization with atom reservoir atomic absorption. Anal. chim. acta 63 (1973) 205-209.

16. ROSS, R. and SHAFIK, T. The determination of chromium in human urine by gas chromatography using a flame photometric detector with a $425.4 \mathrm{~nm}$ filter. J. chromatogr. sci. 11 (1973) 46-48.

17. SAMITZ, M. H. and GROSS, S. Effect of hexavalent and trivalent chromium compounds on the skin. Arch. dermatol. 84 (1961) $404-409$.

18. SCHALLER, K. H., ESSING, H. G., VALENTIN, H. and SCHÄCKE, G. The quantitative determination of chromium in urine by flameless atomic absorption spectroscopy. At. absorpt. newsl. 12 (1973) $147-150$.

19. URONE, P. F. and ANDERS, H. H. Determination of small amounts of chromium in human blood, tissues and unine. Anal. chem. 22 (1950) 1317-1321. 